* Doutorando em Ciências Políticas pela Universidade Federal de Minas Gerais. Mestre em Administração Pública na Escola de Governo da Fundação João Pinheiro. Professor universitário. Advogado.

E-mail: paulo_smendes@ yahoo.com.br

** Doutor em Ciências Humanas: Sociologia e Política pela Universidade Federal de Minas Gerais. Mestre em economia pela Universidade Federal de Minas Gerais. Professor da Escola de Governo Paulo Neves de Carvalho da Fundação João Pinheiro.

E-mail: ricardo.carneiro@fjp. mg.gov.br

\section{A gestão ambiental em Minas gerais e o ROMPIMENTO DA BARRAGEM DE REJEITOS DO FUNDÃo EM MARIANA/MG}

\author{
ENVIRONMENTAL MANAGEMENT IN MINAS \\ GERAIS AND THE BREAKING OF THE FUNDÃO \\ TAILING DAM IN MARIANA/MG
}

\section{Paulo Sérgio Mendes César* Ricardo Carneiro**}

Como citar: CÉSAR, Paulo Sérgio Mendes; CARNEIRO, Ricardo. A gestão ambiental em Minas Gerais e o rompimento da barragem de rejeitos do fundão em Mariana/MG. Revista do Direito Público, Londrina, v. 13, n. 2, p.230-266, ago. 2018. DOI: 10.5433/24157-108104-1.2018v13n2p230. ISSN: 1980-511X.

Resumo: O meio ambiente ecologicamente equilibrado está assegurado em nossa Carta Magna, sendo que incumbe ao Poder Público, juntamente com a coletividade, defendê-lo. Coadunar a proteção do meio ambiente com a necessidade de promover o desenvolvimento econômico tem se mostrado uma tarefa complexa. Seguindo a prescrição constitucional, o artigo discute a gestão ambiental em Minas Gerais, tendo em perspectiva o desastre ambiental provocado pelo rompimento, em 2015, da Barragem de Rejeitos do Fundão, localizada em Mariana/MG. Para a consecução desse objetivo, mediante revisão da literatura 
específica e da análise de dados oficiais, são abordados a sistemática de licenciamento ambiental adotada no país, que está no cerne da Política Nacional de Meio Ambiente, as principais características da estrutura e da atuação do sistema de gestão ambiental mineiro, com ênfase no monitoramento de barragens, e aspectos relevantes concernentes aos processos de licenciamento e controle da referida barragem, construída e operada pela Samarco Mineração S.A. Ademais, após identificadas as fraquezas do sistema de gestão ambiental, as considerações finais reafirmam a importância da regulação ambiental no tocante à promoção do desenvolvimento sustentável e da existência de uma adequada capacidade estatal para sua aplicação.

Palavras-chave: Mineração. Gestão ambiental. Política Nacional de Meio Ambiente. Licenciamento ambiental. Barragem de rejeitos.

Abstract: Living in an ecologically balanced environment is a guarantee established by our Constitution. Henceforth, it is up to our Public Administration, together with local communities, to defend the environment. Moreover, having good coordination for the protection of the environment with the promotion of sustainable economic development has proved to be an arduous task. Furthermore, following the constitutional wording, this paper explores environmental management in Minas Gerais, 
within the context of the Brazilian environmental disaster provoked by the disruption, in 2015, of the Fundão Tailing Dam, located in Mariana/ MG. In order to achieve this objective, this paper utilizes literature review with the analysis of official data. Consequentially, examining the Brazilian environmental licensing system, which is at the core of our National Environmental Policy. This study also investigates the main characteristics of infrastructure and performance of the mining environmental management system, giving emphasis on monitoring, aspects related to licensing and control processes of the dam - built and operated by the company: Samarco Mineração SA. In conclusion, after identifying weaknesses in the environmental management system, our final considerations reaffirm the importance of environmental regulation with regard to the promotion of sustainable development and the existence of adequate state capacity for its application.

Keywords: Mining. Environmental management. National Environmental Policy. Environmental licensing. Waste dam. 


\section{INTRODUÇÃO}

O meio ambiente está estritamente relacionado à qualidade de vida das pessoas. Ao longo da história da humanidade, devido ao desrespeito e à degradação do meio ambiente, o ser humano tem sofrido com impactos negativos em diversas variáveis que afetam suas condições de vida, em especial a saúde, individual e coletiva.

$\mathrm{Na}$ atual configuração política mundial, o Estado deve assumir o papel de maior protetor do meio ambiente, visto que cabe ao Poder Público a tutela dos interesses gerais da coletividade. Por esta razão, o Estado deve zelar pela preservação do meio ambiente, o que implica a regulação e o controle de atividades com significativo potencial de poluição e degradação ambiental, no sentido de conciliar desenvolvimento socioeconômico e uso racional dos recursos naturais, sintetizado na ideia de sustentabilidade.

Reconhecendo a relevância da atuação estatal no controle e preservação do meio ambiente, o artigo se propõe a examinar como o sistema de gestão ambiental de Minas Gerais, valendo-se de seu aparato normativo, institucional e estrutural, tem exercido a tutela ambiental, notadamente no que se refere aos potenciais impactos ambientais oriundos da atividade minerária. Em outros termos, o principal objetivo do trabalho consiste em avaliar o sistema de gestão ambiental do estado quanto à sua capacidade de exercer o controle e fiscalização da exploração mineral, ilustrando a análise com o caso do rompimento da Barragem de Rejeitos do Fundão. Para a consecução desse objetivo, são abordados a sistemática de licenciamento ambiental adotada no país, que está no cerne da regulação estatal condensada na Política Nacional de Meio Ambiente (PNMA), as principais características da estrutura e da atuação do sistema de gestão ambiental mineiro, com ênfase no monitoramento de 
barragens, e aspectos relevantes atinentes aos processos de licenciamento e fiscalização da referida barragem.

O artigo desdobra-se em cinco seções, incluindo esta introdução e as considerações finais. A segunda seção trata da introdução e normatização do licenciamento ambiental no Brasil, entendido e tratado como um dos principais instrumentos de regulação estatal para o meio ambiente, partindo de considerações gerais acerca da adoção, pelos Estados Unidos, da utilização da Avaliação de Impactos Ambientais (AIA) e sua disseminação internacional. Ainda concernente ao arcabouço normativo da sistemática brasileira de licenciamento, são apresentadas propostas legislativas que, sob a justificativa de buscarem maior promoção do desenvolvimento econômico, visam notadamente a dar maior celeridade ao processo. Na terceira seção, examinam-se a estrutura institucional e a atuação do sistema de gestão ambiental de Minas Gerais, destacando aspectos concernentes ao licenciamento, controle e fiscalização de barragens. A quarta seção dirige o foco analítico para o licenciamento e a fiscalização da Barragem de Rejeitos do Fundão, utilizando seu rompimento para reafirmar a importância do Poder de Polícia Ambiental e os limites de sua aplicação no estado, o que é retomado e aprofundado nas considerações finais.

Para a realização do trabalho, adotou-se predominantemente a pesquisa bibliográfica e a documental. Ao lado de levantamentos em legislação específica e revisão de literatura pertinente, foram explorados documentos técnicos relacionados à Barragem do Fundão, destacando escolhas e avaliando em que medida o processo de licenciamento ambiental cumpriu ou não sua finalidade. Também foram pesquisadas informações relacionadas ao sistema mineiro de gestão ambiental, como a caracterização do quadro técnico em exercício. 


\section{A REGULAÇÃO ESTATAL PARA A PRESERVAÇÃo DO MEIO AMBIENTE E O LICENCIAMENTO AM- BIENTAL}

O termo regulação comporta diferentes perspectivas de abordagem (MORAN, 2002; JORDANA; LEVI-FAUR, 2004), que vão desde a noção de autorregulação, entendida como regulação descolada da esfera de atuação estatal, à noção de Estado regulador, que enfatiza a regulação como a característica mais marcante da atividade estatal. Focando a regulação estatal, é possível apontar, como o fazem Jordana e Levi-Faur (2004), duas concepções principais presentes na literatura. A primeira noção a considera como "governança em sentido geral: os esforços agregados das agências estatais no sentido de dirigir a economia" (JORDANA; LEVI-FAUR, 2004, p. 3, tradução nossa). Para a segunda, consiste em "uma forma mais estrita de governança: um conjunto de regras autorizativas, frequentemente acompanhadas por alguma agência administrativa para monitorar e impor sua observância" (JORDANA; LEVI-FAUR, 2004, p. 3, tradução nossa).

Para os propósitos deste trabalho, adota-se a segunda acepção do termo. Trata-se da concepção clássica de regulação, que pode ser sintetizada como a "imposição de uma série de regras juntamente com os mecanismos para fazê-las valer” (MOURA, 2002, p. 85). Tal definição coloca em relevo, de um lado, a especificação da regulamentação básica a ser observada pelos agentes em suas transações ou interações num dado campo de atividade e, de outro, a estruturação de capacidade administrativa para assegurar sua aplicação, ou seja, a capacidade de 
enforcement.

Sobre a questão da regulação estatal, vale mencionar a noção de Poder de Polícia aplicado à questão ambiental, que compreende:

A atividade da Administração Pública que limita ou disciplina direito, interesse ou liberdade, regula a prática de ato ou a abstenção de fato em razão de interesse público concernente à saúde da população, à conservação dos ecossistemas, à disciplina da produção e do mercado. Ao exercício de atividade econômica ou de outras atividades dependentes de concessão, autorização/permissão ou licença do Poder Público de cujas atividades possam decorrer poluição ou agressão à natureza.(MILARÉ, 2001, p. 282, grifo nosso)

No tocante à sustentabilidade, tal ideia expressa o entendimento de ser inaceitável pensar uma atividade econômica descolada da preocupação com a qualidade ambiental, o que implica a adoção de práticas produtivas que avancem além de atender as necessidades presentes de consumo, garantindo as necessidades das gerações futuras. De acordo com o Programa das Nações Unidas para o Meio Ambiente (PNUMA), o termo “desenvolvimento sustentável” refere-se ao tripé de fatores sociais, ambientais e econômicos que devem ser considerados para o alcance da prática sustentável (ONUBR, 2016).

No Brasil, o meio ambiente ecologicamente equilibrado é direito de todos, sendo que a responsabilidade por sua preservação diz respeito não somente ao Estado, mas a toda a coletividade. É o que estabelece o caput do art. 225, da Constituição da República Federativa do Brasil de 1988 (CRF/88), "Todos têm direito ao meio ambiente ecologicamente 
equilibrado, bem de uso comum do povo e essencial à sadia qualidade de vida, impondo-se ao Poder Público e à coletividade o dever de defendêlo e preservá-lo para as presentes e futuras gerações" (BRASIL, 1988).

Dentre as atividades econômicas com relevante potencial de impacto ambiental, sobressai-se a mineração - atividade produtiva que desponta, historicamente, como uma das mais importantes na formação do produto e da renda de Minas Gerais. Contra face de sua importância, o potencial de a exploração minerária ocasionar impacto ambiental revela-se muito expressivo, impondo a necessidade de a administração pública estadual dispor de adequada e suficiente capacidade institucional de controle e monitoramento da atividade. Essa necessidade se evidencia, com nitidez, no rompimento da Barragem de Rejeitos do Fundão, de propriedade da empresa Samarco Mineração S.A - evento ocorrido em 05 de novembro de 2015, no município de Mariana, e que é considerado um dos maiores desastres ambientais do mundo, com danos e prejuízos vultosos do ponto de vista natural, econômico, social e cultural (IBAMA, 2015).

Destarte, uma dimensão crucial da regulação estatal consiste na definição do conjunto de regras que disciplinam e ordenam as interações dos agentes num dado campo de atividade. Da perspectiva da regulação ambiental brasileira, o licenciamento das atividades com potencial de provocar impactos relevantes ao meio ambiente assume papel de destaque.

A inserção da questão ambiental na agenda pública mundial ganha impulso com a edição, nos Estados Unidos,do National Enviromental Policy Act (NEPA), ocorrida em 1969. O NEPA, que pode ser visto como marco referencial do reconhecimento político da importância da regulação ambiental, estabeleceu os princípios e os objetivos da política ambiental norte-americana, tornando a realização de Avaliação de 
Impacto Ambiental (AIA) obrigatória para atividades do governo federal com potenciais efeitos negativos para o meio ambiente (TEIXEIRA, 2008; CARNEIRO, 2015), posteriormente, estendida para projetos de investimento da iniciativa privada (CARNEIRO, 2015). Introduzse, dessa forma, um instrumento capaz de forçar a consideração dos potenciais impactos indiretos de projetos de investimento antes de sua implantação.

O Programa das Nações Unidas para o Meio Ambiente (PNUMA), em 1972, endossa e impulsiona a adoção da prática de estudos ambientais nos processos de gestão ambiental no âmbito internacional (TEIXEIRA, 2008; CARNEIRO, 2015), consoante o que se denomina de isomorfismo institucional, ou seja, a replicação de uma determinada instituição em ambientes distintos. A disseminação da prática ganha reforço com a realização, em 1992, da Conferência das Nações Unidas sobre o Meio Ambiente e o Desenvolvimento, conhecida como Rio-92, na qual foi proposto o uso instrumental da AIA para qualquer atividade com potencial impacto negativo no meio ambiente (CARNEIRO, 2015).

Esse caminho também foi trilhado pelo Brasil, como estabelece a $\mathrm{CRF} / 88$, em seu art. $225, \S 1^{\circ}$, IV, in verbis: "IV - exigir, na forma da lei, para instalação de obra ou atividade potencialmente causadora de significativa degradação do meio ambiente, estudo prévio de impacto ambiental, a que se dará publicidade" (BRASIL, 1988).

Em âmbito infraconstitucional, a Lei Federal n. 6.803, de 02 de julho de 1980, que dispõe sobre as diretrizes básicas para o zoneamento industrial nas áreas críticas de poluição e determina a realização de estudos prévios de impacto ambiental, dá a partida para a normatização da questão anteriormente ao novo texto constitucional (BRASIL, 1980). Essa normatização ganha contornos mais nítidos com a edição da Lei 
Federal n. 6.938, de 31 de agosto de 1981, que dispõe sobre a Política Nacional do Meio Ambiente (PNMA). Com a PNMA, a AIA, designada como Estudo de Impacto Ambiental (EIA), passa a ser efetivamente considerada como instrumento básico da gestão ambiental no país, abrangendo tanto investimento público como privados (BRASIL, 1981).

A Lei n. 6.938/81 foi regulamentada pelo Decreto n. 88.351, de 01 de junho de 1983, no qual houve a vinculação do EIA ao processo de licenciamento ambiental de atividades potencialmente poluidoras. $\mathrm{O}$ referido Decreto prescreveu ainda a compilação dos resultados do EIA no Relatório de Impacto Ambiental (RIMA) e dividiu o licenciamento em três etapas, Licença Prévia (LP), Licença de Instalação (LI) e Licença de Operação (LO)(BRASIL, 1983).A LP é concedida na fase preliminar do planejamento da atividade, contendo requisitos básicos a serem atendidos nas fases de localização, instalação e operação, observados os planos municipais, estaduais ou federais de uso do solo, dentre outros aspectos; a LI autoriza o início da implantação, de acordo com as especificações constantes do Projeto Executivo aprovado, e detalha as ações de controle ambiental e demais condicionantes, da qual constituem motivo determinante; e a LO autoriza o início da atividade licenciada após a verificação do efetivo cumprimento do que consta das licenças anteriores, especificando as medidas de controle ambiental e condicionantes determinados para a operação.

A regulação ambiental estabelecida pelo Decreto n. 88.351/83 será retomada e detalhada por "[...] vários dispositivos normativos posteriores, com destaque para as resoluções promulgadas pelo Conselho Nacional do Meio Ambiente (CONAMA)" (CARNEIRO, 2015, p. 70). Dentre elas, merece destaque a Resolução Conama n. 01, de 23 de janeiro de 1986, a qual estabelece que dependerá de elaboração de EIA e respectivo 
Rima, a serem submetidos à aprovação do órgão ambiental competente, o licenciamento de atividades modificadoras do meio ambiente, tais como a extração de minério, inclusive os da classe II, definidas no Código de Mineração (BRASIL, 1986). A Resolução ainda determina, em seu art. $5^{\circ}$, que o EIA, além de atender à legislação, em especial aos princípios e objetivos expressos na PNMA, obedecerá às seguintes diretrizes gerais:

I - Contemplar todas as alternativas tecnológicas e de localização de projeto, confrontando-as com a hipótese de não execução do projeto;

II - Identificar e avaliar sistematicamente os impactos ambientais gerados nas fases de implantação e operação da atividade;

III - Definir os limites da área geográfica a ser direta ou indiretamente afetada pelos impactos, denominada área de influência do projeto, considerando, em todos os casos, a bacia hidrográfica na qual se localiza; [...] (BRASIL, 1986, grifo nosso).

Cabe ressaltar a determinação para identificação e avaliação sistemática dos impactos ambientais, inclusive durante a operação da atividade econômica, o que remete ao âmbito da LO. Ademais, observa-se que o dimensionamento da região geográfica direta e indireta do potencial impacto ambiental deve considerar inclusive sua bacia hidrográfica.

Nos termos da Lei Complementar Federal n. 140, de 08 de novembro de 2011, o licenciamento ambiental é o procedimento administrativo destinado a licenciar atividades ou empreendimentos utilizadores de recursos ambientais, efetiva ou potencialmente poluidores ou capazes, sob qualquer forma, de causar degradação ambiental (BRASIL, 2011). Trata-se então de uma obrigação legal prévia à instalação de qualquer 
empreendimento ou atividade potencialmente poluidora ou degradadora do meio ambiente, como a mineração. Dessa sorte, verifica-se que a legislação brasileira está alinhada às diretrizes internacionais, como as do PNUMA, visto que ela possui uma sistemática do processo de licenciamento que facilita, em teoria, o monitoramento pelos órgãos ambientais responsáveis.

Segundo Milaré (2001, p. 283), o licenciamento ambiental revelase como importante ferramenta estatal no exercício do Poder de Polícia Ambiental, conforme transcrito abaixo:

O poder de polícia administrativa ambiental é exercido mais comumente por meio de ações fiscalizadoras, uma vez que a tutela administrativa do ambiente contempla medidas corretivas e inspectivas, entre outras. Malgrado isso, dentre os atos de polícia em meio ambiente, o licenciamento também ocupa lugar de relevo, uma vez que as licenças são requeridas como condições para praticar atos que, não observadas às respectivas cláusulas, podem gerar ilícitos ou efeitos imputáveis. O licenciamento ambiental visa a preservar de riscos potenciais ou efetivos a qualidade do meio e a saúde da população, riscos estes oriundos de qualquer empreendimento ou intervenção que altere desfavoravelmente as condições do ambiente.

No entanto, ressurge com força no período pós rompimento da barragem de rejeitos em Mariana a discussão sobre o novo marco regulatório da mineração, especificamente, o Projeto de Lei n. ${ }^{o}$ 5.807/13. Na contramão da preservação do meio ambiente, o projeto abrange principalmente aspectos sobre celeridade no licenciamento e remodelagem tributária, deixando de lado questões importantes como a 
segurança e saúde de trabalhadores, prevenção de grandes acidentes ou fortalecimento dos órgãos públicos de gestão ambiental (BRASIL, 2013).

No mesmo rumo, ganha força no Congresso a discussão de propostas que buscam o reenquadramento institucional do licenciamento ambiental. Na Câmara Federal, encontra-se em tramitação o Projeto de Lei n. 3.279/2004, conhecido como Lei Geral do Licenciamento. No Senado, as iniciativas reformistas compreendem a Proposta de Emenda à Constituição n. ${ }^{\circ}$ 65/2012 (PEC 65/12) e três projetos de lei que versam sobre o licenciamento ambiental de empreendimentos considerados estratégicos para o desenvolvimento nacional, mais especificamente os PLs n. 602/2015, n. 603/2015 e n. 654/2015.

De um modo geral, as propostas reformistas em tramitação no Congresso percebem o licenciamento como um obstáculo à realização de investimentos no país, em virtude da morosidade dos órgãos ambientais na análise dos estudos ambientais e na emissão de pareceres e licenças. A atuação dos referidos órgãos ambientais seria excessivamente burocrática, no sentido de uma orientação mais focada no processo que nos resultados. Para lidar com o problema, o que se encaminha como solução, nas propostas do legislativo, é a simplificação da sistemática do licenciamento, esvaziando sua instrumentalidade na prevenção e controle dos impactos ambientais, como posto na PNMA. A questão da realização de investimentos na melhoria da capacidade técnica e operacional dos órgãos ambientais, com o intuito de adequa-la à demanda por emissão de licença, sequer é mencionada.

Em Minas Gerais, também, são observadas alterações legislativas visando dar maior celeridade ao licenciamento ambiental. Nesse sentido, a Lei n. ${ }^{\circ}$ 21.972/16, de 21 de janeiro de 2016, instituiu o licenciamento 
concomitante e a Licença Ambiental Simplificada ${ }^{1}$, que substitui a Autorização Ambiental de Funcionamento ${ }^{2}$ e deve ser realizada eletronicamente em fase única (MINAS GERAIS, 2016a).

Merece atenção especial o conteúdo estabelecido no art. 10, do Decreto n. ${ }^{\circ} 46.993 / 2016$, que isenta os órgãos estaduais no licenciamento e na fiscalização ambiental de aspectos relativos à segurança estrutural e operacional das barragens de rejeitos (MINAS GERAIS, 2016c). Tal dispositivo imputa ao empreendedor privado a responsabilidade pela segurança estrutural e operacional, mas fere gravemente o princípio do Poder de Polícia Ambiental estabelecido no art. 225 da CRF/88. Conforme Meirelles (2003), o Poder de Polícia é considerado ato vinculado do qual não cabe discricionariedade do administrador público, e deve, portanto, ser chamado de Dever de Polícia.

\section{CAPACIDADE ESTATAL E GESTÃO AMBIENTAL EM MINAS GERAIS EM RELAÇÃO ÀS BARRAGENS}

Outra dimensão crucial da regulação estatal, como mencionado na seção introdutória, refere-se à capacidade estatal para assegurar a aplicação das regras estabelecidas pelo poder público. A capacidade estatal assenta-se na estruturação do aparato técnico e administrativo do poder público, em articulação com os mecanismos e instrumentos operacionais passíveis de ser mobilizados em sua atuação.

Competem às unidades federadas o licenciamento ambiental e o

1 A Licença Ambiental Simplificada poderá ser viabilizada eletronicamente, em uma única fase, por meio de cadastro ou da apresentação do Relatório Ambiental Simplificado pelo empreendedor, segundo critérios e pré-condições estabelecidos pelo órgão ambiental competente (Art. 20, da Lei n. ${ }^{\circ}$ 21.972/16).

2 A Autorização Ambiental de Funcionamento era um processo mais simples e rápido para a regularização destinado a atividades consideradas de impacto ambiental não significativo (Deliberação Normativa Copam $74 / 04)$. 
controle regular sobre as atividades potencialmente impactantes ao meio ambiente. Em Minas Gerais, a Lei Delegada n. 125, de 25 de janeiro de $2007^{3}$, atribui à então criada Secretaria de Estado de Meio Ambiente e Desenvolvimento Sustentável (SEMAD)a missão de formular e coordenar a política estadual de proteção e conservação do meio ambiente, de gerenciar os recursos hídricos e de articular as políticas de gestão dos recursos ambientais, visando ao desenvolvimento sustentável no estado (MINAS GERAIS, 2007). A implementação dessa missão se faz por meio do Sistema Estadual de Meio Ambiente e Recursos Hídricos (SISEMA).

De acordo com a Lei n. ${ }^{\circ} 21.972$, de 21 de janeiro de 2016,o Sisema é o conjunto de órgãos e entidades responsáveis pelas políticas de meio ambiente e de recursos hídricos do estado (MINAS GERAIS, 2016a). A citada Lei determina, ainda, que o referido sistema deve atuar de forma integrada, transversal e participativa.

A estrutura funcional e operacional do Sisema envolve a Semad e seus vários órgãos vinculados - a Fundação Estadual do Meio Ambiente (FEAM), o Instituto Estadual de Florestas (IEF) e o Instituto Mineiro de Gestão das Águas (IGAM), o Conselho Estadual de Política Ambiental (COPAM) e o Conselho Estadual de Recursos Hídricos (CERH), além da Polícia Militar de Minas Gerais (PMMG) e dos núcleos de gestão ambiental das demais secretarias de estado. Integram também o Sisema os comitês de bacias hidrográficas, as agências de bacias hidrográficas e as entidades equiparadas.

De acordo com o inciso XXI, do art. $2^{\circ}$, da Lei Delegada . $^{\circ}$ 125/07, a Semad deve:

[...]promover, por meio do Comitê Gestor da Fiscalização

3 Lei revogada pela Lei Delegada ${ }^{\circ} 180$, de 20 de janeiro de 2011. 
Ambiental Integrada - CGFAI, o planejamento e o monitoramento da fiscalização ambiental integrada do Estado, coordenando a atuação da FEAM, do IEF, do IGAM e da Polícia Ambiental da Polícia Militar de Minas Gerais e de outros órgãos e entidades da Administração estadual, em articulação com o Governo Federal por meio do IBAMA. (MINAS GERAIS, 2007, grifo nosso).

Ainda no âmbito da Semad, foram criadas, pela Lei n. 22.073, de 28 de abril de 2016, que altera a Lei n. 21.972/16, duas importantes diretorias visando a dar suporte às atividades de controle e gestão da qualidade ambiental no estado, mais especificamente, a Diretoria de Controle, Monitoramento e Geotecnologia e a Diretoria de Operações e Eventos Críticos (MINAS GERAIS, 2016b).

No que tange à atividade mineradora, o art. $5^{\circ}$, do Decreto Estadual 45.825, de 20 de dezembro de 2011, que contém o Estatuto da Feam, estabelece, dentre suas finalidades, executar a política de proteção, conservação e melhoria da qualidade ambiental, no que concerne à gestão do ar, do solo, dos resíduos sólidos, bem como de prevenção e de correção da poluição ou da degradação ambiental provocada pelas atividades industriais, minerárias e de infraestrutura (MINAS GERAIS, 2011). Por esta razão, a Feam realiza, além do controle ambiental por meio de monitoramento e fiscalizações, auditorias de segurança para reduzir a probabilidade de ocorrência de acidentes a partir do monitoramento sistemático de estruturas, como as barragens de rejeitos e similares.

De acordo com o Inventário de Barragem do Estado de Minas Gerais de 2015, elaborado pela Feam, o Sisema, em função dos acidentes já ocorridos e do potencial de dano ambiental e social que podem ocasionar, tem priorizado a gestão de barragens de rejeitos e de resíduos em 
indústrias e mineração, por meio do acompanhamento dos relatórios de auditoria técnica de segurança e realização de fiscalizações nas estruturas. Assim, desde 2002 vem sendo desenvolvido o Programa de Gestão de Barragens de Rejeitos e Resíduos, com o objetivo de reduzir o risco de danos ambientais em decorrência de acidentes nessas estruturas (FEAM, 2016).

As barragens são cadastradas no Banco de Declarações Ambientais (BDA) e passam por auditoria periódica de segurança, na frequência estabelecida na legislação em vigor, e as informações destas auditorias também são nele inseridas. Partindo das informações do BDA, a Feam elabora uma programação anual de fiscalizações, priorizando as estruturas que apresentam condição de estabilidade não garantida, seja do ponto de vista da estrutura física do maciço, seja do ponto de vista da capacidade hidráulica para amortecimento de cheias (FEAM, 2016).

Os critérios de classificação de barragens de contenção de rejeitos, de resíduos e de reservatório de água em empreendimentos industriais e de mineração em Minas Gerais foram objeto da Deliberação Normativa n. 62, de 17 de setembro de 2002, editada pelo Copam, por meio da Deliberação Normativa n. 87, de 17 de julho de 2005. Além de critérios para definição do porte da barragem e do reservatório, classificados em pequeno, médio e grande porte, a Deliberação também especifica parâmetros para o potencial de dano ambiental, conforme dispõe o art. $3^{\circ}$ :

1. Baixo potencial de dano ambiental - Classe I: somatório dos valores dos parâmetros for menor ou igual a 2 .

2. Médio potencial de dano ambiental - Classe II: somatório dos valores dos parâmetros for maior que 2 e menor ou igual a 5 . 
3. Alto potencial de dano ambiental - Classe III: somatório dos valores dos parâmetros for maior que 5. (MINAS GERAIS, 2005).

Por sua vez, a Deliberação Normativa Copamn ${ }^{\circ}$ 87, de 17 de junho de 2005, estabelece que todas as barragens devem ser objeto da realização de Auditoria Técnica de Segurança, conforme disposto no art. $5^{\circ}$, de acordo com a periodicidade que varia em função da classificação da barragem, sendo:

1. Auditoria a cada 1 ano para Barragens de Classe III;

2. Auditoria a cada 2 anos para Barragens de Classe II e

3. Auditoria a cada 3 anos para Barragens de Classe I. (MINAS GERAIS, 2005).

A Deliberação Normativa n ${ }^{\circ}$ 87/2005 define ainda que as Auditorias Técnicas de Segurança devem ser feitas por profissionais externos ao quadro de funcionários da empresa para garantir clareza e evitar conflito de interesses e executadas por especialistas em segurança de barragens (MINAS GERAIS, 2005).Já a Deliberação Normativa Copamnº 124, de 09 de outubro de 2008, estabelece que o empreendedor deverá apresentar à Feam a Declaração de Condição de Estabilidade ${ }^{4}$ referente à última atualização do Relatório de Auditoria Técnica de Segurança até o dia 10 de setembro de cada ano de sua elaboração (MINAS GERAIS, 2008).

Nesse sentido, o relatório técnico da Diretoria de Qualidade e Gestão Ambiental (DQGA) no 08/2007 condensa as conclusões dos auditores

4 A Declaração de Condição de Estabilidade deve ser apresentada pelos responsáveis por empreendimentos industriais e minerários que possuem barragens de contenção de rejeitos e de resíduos (Deliberação Normativa Copam87/2005 e Deliberação Normativa Copam 124/2008). 
quanto às condições de estabilidade da estrutura das barragens em Minas Gerais no ano de 2006 e constata que, “[...]das 606 estruturas cadastradas na Feam, 478 (79\%) apresentam-se estáveis, 55 (9\%) não possuem garantia de estabilidade e $73(12 \%)$ não obtiveram conclusão sobre sua estabilidade, principalmente devido à falta de dados técnicos e de monitoramento" (FEAM, 2007, p. 1, grifo nosso).

De acordo com o citado relatório, não foi garantida a estabilidade de 55 barragens, das quais 27 (49\%) enquadram-se na Classe III, 20 (36\%) na Classe II e as restantes na Classe I. Seguindo, o relatório afirma que:

Para essas estruturas foi solicitada a comprovação imediata da implementação das ações/procedimentos recomendados pelo auditor de forma que a estrutura apresente nível de segurança adequado, com Anotação de Responsabilidade Técnica do responsável pela implementação das ações, bem como do responsável pela operação da estrutura .(FEAM, 2007, p. 2)

O mesmo relatório ainda traz uma análise da situação em 2007, mostrando a redução do número de barragens sem auditoria concluída, de 73para 41, e o aumento do número de barragens sem garantia de estabilidade, de 55 para 58, conforme Figura 1.

Figura 1: Situação das barragens quanto à estabilidade - 2007 


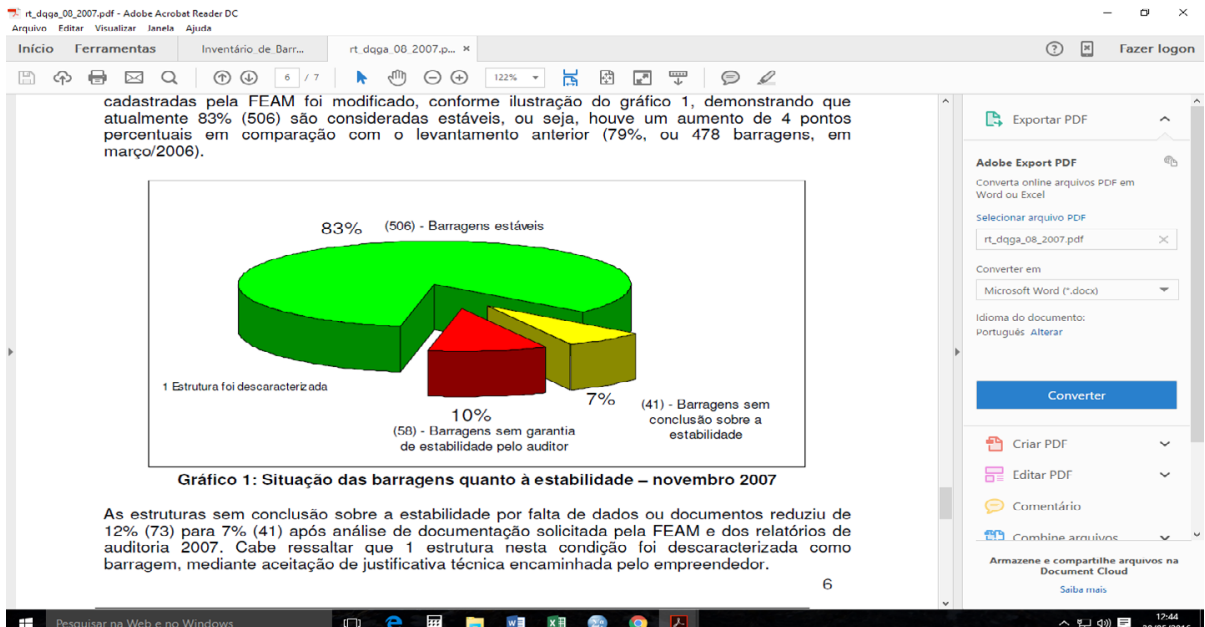

Fonte: Feam, 2007

Considerando o potencial da atividade de extração de minério de ferro em Minas Gerais, pode-se observar, na Figura 2, que a atividade mineradora possui 157 estruturas de classe III cadastradas no BDA.

Figura 2: Gráfico da distribuição das estruturas por Classe e Tipologia - 2015 


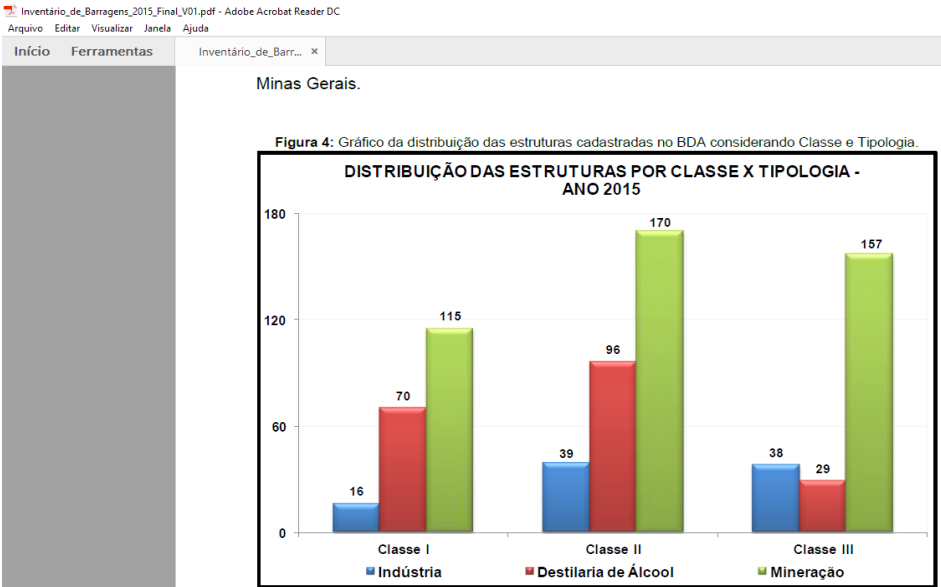

Fonte: Feam, 2016

A combinação da existência de157 estruturas da mineração, de classe III, com alto potencial de dano ambiental, com a média de aproximadamente $10 \%$ sem estabilidade garantida, pode ser considerada uma situação muito preocupante a exigir uma atuação mais incisiva do Poder Público. Convergindo com essa percepção, o Inventário de Barragens de 2015 (FEAM, 2016) frisa que a barragem que não atender aos requisitos de segurança deverá ser recuperada ou desativada pelo seu empreendedor, o qual deverá comunicar ao órgão fiscalizador as providências adotadas.

No que tange ao capital humano dedicado à gestão do meio ambiente nos órgãos estaduais, segundo dados disponibilizados pelo Portal da Transparência do Estado de Minas Gerais (MINAS GERAIS, 2016d), em dezembro de 2015 havia 2.262 servidores em exercício no Sisema, distribuídos conforme informações da Tabela 1. 
Tabela 1 - Distribuição de servidores do Sisema por cargo em dezembro de 2015

\begin{tabular}{|l|c|c|}
\hline \multicolumn{1}{|c|}{ Cargo } & $\begin{array}{c}\text { Número de } \\
\text { servidores }\end{array}$ & $\begin{array}{c}\text { \% em } \\
\text { relação } \\
\text { ao } \\
\text { total }\end{array}$ \\
\hline Analista Ambiental & 669 & $29,7 \%$ \\
\hline Gestor Ambiental & 525 & $23,3 \%$ \\
\hline Técnico Ambiental & 287 & $12,7 \%$ \\
\hline Auxiliar Ambiental & 241 & $10,6 \%$ \\
\hline $\begin{array}{l}\text { Outras carreiras com funções não } \\
\text { finalísticas ambientais }\end{array}$ & 243 & $10,7 \%$ \\
\hline Recrutamento Amplo (não concursados) & 296 & $13 \%$ \\
\hline Total de Servidores Sisema & $\mathbf{2 . 2 6 1}$ & \\
\hline
\end{tabular}

Fonte: Portal da Transparência (MINAS GERAIS, 2016d). (Construção dos autores).

Merece destaque que, das carreiras listadas na Tabela 1, menos de $3 \%$ dos servidores do Sisema, precisamente 61 servidores de carreiras ambientais, estavam em exercício em unidades administrativas mais relacionadas ao controle, à fiscalização e ao monitoramento de atividades que potencialmente impactam o meio ambiente.

Considerando as dimensões territoriais de Minas Gerais - da ordem de $586.528 \mathrm{~km}^{2}$ - (IBGE, 2016), bem como o número registrado em 2015 de 157 barragens de rejeitos de classe III, com alto potencial danoso, pode-se dizer que o quantitativo de apenas 61 servidores do Sisema identificados em exercício, no ano de 2015, em atividades de prevenção, fiscalização e controle ambiental traduz insuficiência da capacidade fiscalizatória estatal. A avaliação torna-se ainda mais crítica 
ao se constatar que somente sete servidores, representando $0,30 \%$ do corpo técnico do Sisema, encontravam-se em exercício na Gerência de Resíduos Sólidos Industriais e da Mineração da Feam, que é a unidade responsável pelo monitoramento de barragens como a do Fundão.

\section{A RUPTURA DA BARRAGEM DE REJEITOS DO FUN- DÃO E A FRAGILIDADE DO SISTEMA DE GESTÃO AMBIENTAL}

A Barragem de Rejeitos do Fundão enquadra-se na classe III, de alto potencial de dano ambiental, e, como já comentado, sua ruptura é considerada um dos maiores desastres ambientais do mundo (IBAMA, 2015). Proprietária da barragem, a Samarco Mineração S.A. é um complexo industrial integrado de lavra, beneficiamento, bombeamento, pelotização e embarque de minério de ferro. As atividades de lavra e beneficiamento são feitas no Complexo Minerador Germano-Alegria, localizado nos municípios de Mariana e Ouro Preto (SUPRAM, 2011). O complexo possui as barragens de rejeitos de Germano, Fundão e Santarém, todas vizinhas.

De acordo com a Feam (2016), a Barragem do Fundão continha 45 milhões de $\mathrm{m}^{3}$ de rejeitos de mineração de ferro que foram lançados diretamente no meio ambiente. Wanderley (2016) apontou a dificuldade dos órgãos de controle ambiental mineiros para fiscalizar as represas de rejeito de minério da Samarco, bem como a falta de divulgação clara para o acompanhamento da sociedade. De acordo com levantamentos realizados pelo autor, durante toda trajetória do licenciamento da barragem, iniciado em 2005, foram lavrados apenas 18 autos de infração, 
sinalizando desempenho insatisfatório no processo de fiscalização.

.O licenciamento referente à Barragem do Fundão compreendeu a concessão de licença para sua operação, para sua otimização e para sua unificação e alteamento com a Barragem Germano. Para tanto, foram elaborados, respectivamente, os EIAs da implantação e operação da Barragem de Rejeito do Fundão, datado de 2005; o EIA do Projeto de Otimização da Barragem de Rejeito do Fundão, de dezembro de 2012; e o EIA de Unificação e Alteamento das Barragens de Rejeito do Fundão e Germano, de outubro de 2013 - EIA.

De acordo com o EIA(FEAM, 2005), previu-se que a segurança dos reservatórios de rejeitos seria monitorada pela adequada instrumentação do nível freático nas estruturas por meio da instalação de dois tubos ou piezômetros do tipo casa grande associados a piezômetros pneumáticos. $\mathrm{O}$ recalque e movimento dessas estruturas seriam "[...] monitorados e acompanhados pela instalação de indicadores superficiais de movimento [...]" (FEAM, 2005, p. 48).Vale relembrar que, segundo critério de periodicidade adotado pela Feam para estruturas de classe III, com alto potencial de dano ambiental, deveriam ocorrer auditorias a cada ano visando ao adequado monitoramento.

O EIA (FEAM, 2005) ainda previu que os objetivos do plano de abandono da área de disposição de rejeitos deveriam considerar questões envolvendo o uso do solo, com destaque para a estabilidade física, ambiental e socioeconômica das áreas afetadas. $\mathrm{O}$ abandono futuro do reservatório de rejeitos do Fundão estaria intimamente ligado ao abandono do reservatório vizinho, do Germano, visto que, devido ao caráter operacional do sistema de rejeitos do Fundão, haveria a formação de uma praia com inclinação no sentido do reservatório do Germano. Previa-se então, que todo o fluxo captado pela bacia hidrográfica do 
Fundão fosse conduzido pelo interior do reservatório do Germano.

Segundo classificação da AIA, apensa ao EIA (FEAM, 2005), impactos negativos de intensidade muito alta, com consequências catastróficas e acima da capacidade de absorção do ambiente/ comunidades, de abrangência extrarregional, extrapolando a Área de Influência Indireta do empreendimento, e de significância catastrófica, não foram considerados nem na avaliação de impactos reais nem na avaliação de impactos potenciais. Caso tivessem sido efetivamente considerados, isto poderia inviabilizar o empreendimento. Tal omissão suscita questionamentos acerca da efetividade dos estudos ambientais na sistemática dos processos de licenciamento.

Todavia, o estudo da Avaliação Preliminar de Perigos da Operação (APPO)da Barragem do Fundão (FEAM, 2005, p. 214) considerou o perigo/cenário acidental de um "grande rompimento da barragem com efeito dominó", inclusive com rompimento da barragem vizinha de Santarém, destacando a possibilidade de ocorrência de falha estrutural, manutenção inadequada ou excesso de material assoreado. $\mathrm{O}$ estudo ainda considerou, dentre os potenciais efeitos, o carreamento de sólidos e lama nos cursos d'água, danos a instalações, além de ferimento e morte na população a jusante. A manutenção adequada e o controle de material assoreado deveriam ser fiscalizados pelo órgão ambiental. No entanto, a despeito da sinalização para a possibilidade de ocorrência, na APPO, de grande acidente na barragem, o fato de isto não estar presente na AIA revela outra fraqueza na qualidade dos estudos ambientais que alimentam o processo de licenciamento, comprometendo sobremaneira a gestão ambiental estatal.

Como recomendações de medidas preventivas ao apontado na APPO, o EIA (FEAM, 2005) prescreveu apenas o monitoramento 
periódico da estabilidade e do assoreamento da barragem e a manutenção do sistema de extravazão 5 . Em atenção ao determinado, foi elaborado Programa de Monitoramento e Controle de Processos Erosivos visando à implementação de uma série de medidas e ações preventivas e de controle ambiental. O programa previa monitoramento do volume ocupado pelo rejeito disposto no sistema, medições de vazão que aportam e são descartadas, medições de vazão da água drenada do reservatório, monitoramento sistemático dos piezômetros instalados no maciço do barramento e dos marcos de recalques, e a execução de auditorias técnicas de segurança na barragem. Novamente, verificou-se que o exercício do Poder de Polícia Ambiental ficou bem aquém do necessário para consolidação da garantia do meio ambiente ecologicamente protegido.

Justificada pela continuidade das operações da mineradora e pelo comprometimento do limite das capacidades de recebimento de rejeitos pelas barragens do Germano, Fundão e Santarém, foi proposto, em 2012, o Projeto de Otimização da Barragem de Rejeito do Fundão.

O EIA do Projeto de Otimização (FEAM, 2012) previu três alternativas técnicas e locacionais para o empreendimento. AAlternativa 1, denominada Otimização da Barragem de Rejeito do Fundão, consistia na disposição de rejeito arenoso a jusante da Barragem do Fundão existente. A Alternativa 2, chamada Pilha Lateral, buscava a maximização de volumes em dois diques de partida constituídos com seção típica de aterro compactado e se localizaria próxima à ombreira esquerda da barragem do Germano. Já a Alternativa 3 ou Pilha Área Muller se localizaria próxima à Comunidade de Bento Rodrigues e consistia na construção de um maciço formado por alteamentos sucessivos para

5 Cano inserido ao nível da cota máxima de um reservatório para que por ele escape o excedente de água, no caso de a torneira de boia enguiçar, evitando assim, o transbordamento.

Revista do Direito Público, Londrina, v.13, n.2, p.230-266, ago.2018| DOI: 10.5433/1980-511X.2018v13n2p230 
montante com rejeito arenoso. Sabendo-se que, ao fim, houve a escolha da Alternativa 1, merece atenção aqui uma rápida análise do conjunto de vantagens e desvantagens de cada alternativa.

Nesse sentido, pode-se destacar que, dentre as vantagens da Alternativa 1 encontra-se o argumento que não seriam necessárias intervenções em novas áreas para implantação de linhas de rejeitoduto e acessos, visto que seriam utilizados aqueles já existentes, bem como a capacidade de armazenamento de rejeito ser bem superior à Alternativa 3 e pouco inferior à Alternativa 2, o que a colocava como a mais interessante para o empreendedor. De acordo com trecho extraído do EIA (FEAM, 2012, p. 9):

Além das questões ambientais, que condicionaram a escolha da Alternativa 1, tecnicamente, as questões como volume armazenado, distância do empreendimento da Samarco (possibilidade de aproveitar as estruturas do rejeitoduto) e custos para execução dos projetos foram os fatores que influenciaram na escolha do Projeto Otimização da Barragem de Rejeito do Fundão.

Cabe frisar que a Alternativa 3, além de apresentar a menor capacidade de armazenamento de rejeitos, ainda se situava muito próxima à comunidade de Bento Rodrigues, cerca de $0,5 \mathrm{~km}$ - fato que inviabilizava fortemente tal alternativa. Quanto à Alternativa 2, apesar de possuir capacidade de armazenamento superior à Alternativa 1, previa intervenção muito maior em áreas de preservação permanente (APPs), mais que o dobro. De toda sorte, há de se reforçar que a Aternativa 1, então escolhida, representava a única que produziria impactos cumulativos com a barragem de Santarém, a jusante, com possibilidade de efeito dominó, como já destacado no EIA (FEAM, 2005). 
As medidas mitigadoras abarcaram plano de reabilitação de áreas alteradas, controle de processos erosivos e assoreamento, gestão da qualidade do ar, monitoramento da qualidade das águas, controle de ruído, gestão de resíduos sólidos e monitoramento geotécnico do barramento (SUPRAM, 2013). Porém, de acordo com Wanderley (2016), as medidas de mitigação também não contemplavam um acidente de rompimento da barragem.

Parecer do IEF (2014), consubstanciado ao processo Copamn. ${ }^{\circ}$ 00015/1984/093/2012, reforçava que as barragens da Samarco estavam próximas do atingimento de sua capacidade. Na mesma linha, o EIA (FEAM, 2013) do Projeto de Unificação e Alteamento das Barragens de Rejeito de Germano e Fundão adotou, como sua principal premissa, a necessidade de maximização do volume de armazenamento de rejeitos nessas barragens, visto que estavam muito próximas do exaurimento de suas capacidades.

Não bastasse, o parecer IEF $(2014$, p. 10) ainda apontou que:

A supressão da vegetação, remoção e estocagem dos solos pelo decapeamento, terraplanagem e obras civis para implantação do sistema de drenagem interno, do sistema extravazor e do dique de partida para o Projeto Otimização da Barragem de Rejeito do Fundão, bem como a instalação de estruturas de apoio (canteiros e acessos operacionais), além do trânsito de veículos e máquinas que promove a compactação da camada superior dos solos, são responsáveis pela geração do impacto de alteração das estruturas dos solos, tornando-o mais suscetível ao desenvolvimento de erosões/ou instabilidades geotécnicas (movimentos de massa). 
Nessa linha, o parecer IEF (2014) pontuou que as atividades inerentes à operação da barragem contribuíram para o aumento da erodibilidade do solo. De acordo com o EIA (FEAM, 2005), a região de inserção do empreendimento foi avaliada como alto potencial para a ocorrência de cavidades, devido à presença de rochas quartzíticas presentes na barragem do Fundão. Considerando as áreas de influência, apontou-as como tendo forte potencialidade de ocorrência de cavernas.

No que tange aos impactos sociais, o EIA(FEAM, 2005) já destacava que a comunidade de Bento Rodrigues convivia com grande volume de poeira no período seco e de lama no período chuvoso. A principal causa seria a falta pavimentação asfáltica e o fluxo de caminhões (SUPRAM, 2013).

Ainda que de natureza exploratória, a análise dos resultados da atuação do sistema de gestão ambiental de Minas Gerais evidencia que em diversos momentos do processo de licenciamento da barragem do Fundão surgiram questões que deveriam ter provocado uma atuação mais incisiva do Poder Público, mas que não o provocaram. Ademais, outro ponto de atenção são os relatórios ambientais sem o preciso dimensionamento do impacto potencial, visto que, em muitas situações, pode ocorrer sua subestimação, como nos estudos da barragem do Fundão. Tal fato demanda uma necessidade de melhoria da qualidade dos estudos, com construção de mais cenários considerando as piores situações possíveis.

A despeito de toda sistemática do tríplice licenciamento e da existência de banco de dados e relatórios de acompanhamento, resta clara a indispensabilidade do Poder de Polícia Ambiental, adequadamente aparelhada com capital humano e instrumentalizada para agir com maior rigor no tocante às medidas de caráter cautelar. 


\section{CONCLUSÃO}

A despeito dos avanços relativos ao processo de licenciamento e da legislação ambiental no Brasil, as informações examinadas referentes ao sistema de gestão ambiental de Minas Gerais sinalizam na direção de uma gestão ambiental bem aquém do necessário, principalmente no que se refere ao Poder de Polícia Ambiental. As atividades dos órgãos encarregados da gestão ambiental no estado são prejudicadas por insuficiência operacional, que afeta diretamente a capacidade de monitoramento e fiscalização dos empreendimentos impactantes. Como observado, menos de 3\% dos servidores lotados nos órgãos ambientais mineiros atuavam, em 2015, em atividades mais diretamente relacionadas à fiscalização e ao controle. Considerando que, no mesmo ano, foram identificadas 157 estruturas de classe III, com alto potencial de dano ambiental, e que, segundo relatório da Feam, com informações relativas a 2006 e 2007, em média 10\% das barragens de rejeitos não possuem garantia de estabilidade, torna-se evidente a necessidade de intensificação da atividade de controle e monitoramento no estado.

Em linha auxiliar ao reforço da capacidade estatal de exercício do Poder de Polícia Ambiental, recentemente em Minas Gerais, por meio do art. 30, da Lei n. ${ }^{\circ}$ 21.972/16, ficou expressa a determinação para o fomento de alternativas à implantação de barragens. Tal dispositivo visa principalmente à redução dos impactos ambientais gerados por destinação de rejeitos da mineração em barragens. Em sentido oposto, o Decreto n. ${ }^{\circ}$ 46.993/2016 isenta os órgãos estaduais no licenciamento e na fiscalização ambiental de aspectos relativos à segurança estrutural e operacional das barragens de rejeitos. Tal fato fere gravemente princípio consagrado na $\mathrm{CRF} / 88$ da proteção estatal ao meio ambiente 
ecologicamente equilibrado.

Cabe frisar que, considerando que o Estado, dentro de suas competências institucionais, deve buscar o desenvolvimento econômico mediante uma série de iniciativas para o desenvolvimento local e regional em bases sustentáveis, conjugando, para tanto, esforços comuns entre as estruturas de governo em prol da ampliação da atividade econômica, geração de empregos e qualidade de vida de toda a população, grandes empreendimentos estratégicos como a atividade mineradora não podem ser simplesmente evitados. Todavia, a sustentabilidade do desenvolvimento deve se pautar no tripé econômico, ambiental e social. Isso implica dizer que a despeito da importância da atividade econômica mineradora para a economia mineira, recai sobre o Poder Público a responsabilidade pela observância de aspectos ambientais e sociais quando do licenciamento dos empreendimentos setoriais.

Para que o Estado consiga atender ao precípuo papel de tutor do meio ambiente, atendendo também sua função de promotor do desenvolvimento econômico, mostra-se fundamental o aporte de investimentos nos órgãos ambientais capaz de proporcionar-lhes ferramentas, estruturas e capital humano para a adequada realização de sua função de gestão ambiental. A ruptura da Barragem do Fundão não é e não pode ser tratada como um acidente ou uma fatalidade. É indiscutivelmente uma tragédia ambiental por suas consequências, cuja ocorrência se dá nas brechas da inadequada capacidade estatal de regulação.

\section{REFERENCIAS}

BRASIL. Constituição (1988). Constituição da República

Federativa do Brasil. Brasília, DF: Senado Federal, 1988. 
Disponível em: $<$ http://www.planalto.gov.br/ccivil_03/constituicao/ constituicaocompilado.htm>. Acesso em: 2 mar. 2016.

. Decreto n..$^{\circ} 88.351$,de 01 de junho de 1983. Regulamenta a Lei ${ }^{\circ} 6.938$, de 31 de agosto de 1981, e a Lei $\mathrm{n}^{\circ} 6.902$, de 27 de abril de 1981, que dispõem, respectivamente, sobre a Política Nacional do Meio Ambiente e sobre a criação de Estações Ecológicas e Áreas de Proteção Ambiental, e dá outras providências. Diário Oficial [da] União, Brasília, DF, 3 jun. 1983. Seção 1, p. 9417. Disponível em: $<$ http://www2.camara.leg.br/legin/fed/decret/1980-1987/decreto88351-1-junho-1983-438446-publicacaooriginal-1-pe.html>. Acesso em: 3mar. 2016.

. Lei $\mathrm{n}^{\circ} 6.803$, de 02 de julho de 1980. Dispõe sobre as diretrizes básicas para o zoneamento industrial nas áreas críticas de poluição, e dá outras providências. Diário Oficial [da] União, Brasília, DF, 3 jul. 1980. Disponível em: <http://www.planalto.gov.br/ ccivil_03/leis/16803.htm>. Acesso em: 8mar. 2016.

. Lei ${ }^{\circ}$ 6.938,de 31 de agosto de 1981. Dispõe sobre a Política Nacional do Meio Ambiente, seus fins e mecanismos de formulação e aplicação, e dá outras providências. Diário Oficial [da] União, Brasília, DF, 2 set. 1981. Disponível em: <http://www.planalto.gov.br/ ccivil_03/leis/16938.htm>. Acesso em: 7mar. 2016.

. Lei Complementar Federal n. ${ }^{\circ}$ 140, de 08 de novembro de 2011. Fixa normas, nos termos dos incisos III, VI e VII do caput e do parágrafo único do art. 23 da Constituição Federal, para a cooperação entre a União, os Estados, o Distrito Federal e os Municípios nas ações administrativas decorrentes do exercício da competência comum relativas à proteção das paisagens naturais notáveis, à proteção do meio ambiente, ao combate à poluição em qualquer de suas formas e à preservação das florestas, da fauna e da flora; e altera a Lei nº $\mathbf{6 . 9 3 8 ,}$ 
de 31 de agosto de 1981. Diário Oficial [da] União, Brasília, DF, 9 dez. 2011. [Retificado em 12 dez. 2011]. Disponível em: <http://www. planalto.gov.br/ccivil_03/Leis/LCP/Lcp140.htm>. Acesso em: 3mar. 2016.

. Congresso. Câmara dos Deputados. Projeto de Lei n. ${ }^{\circ}$ 5.807, de 19 de junho de 2013. Dispõe sobre a atividade de mineração, cria o Conselho Nacional de Política Mineral e a Agência Nacional de Mineração - ANM, e dá outras providências. Atividade Legislativa. Brasília, DF, 2013. Disponível em: $<$ http://www.camara.gov.br/ proposicoesWeb/fichadetramitacao?idProposicao=581696>. Acesso em: 16mar. 2016.

. Conselho Nacional do Meio Ambiente. Resolução no 01, de 23 de janeiro de 1986. Dispõe sobre critérios básicos e diretrizes gerais para o Relatório de Impacto Ambiental - RIMA. Diário Oficial [da] União, Brasília, DF, 17 fev. 1986. Disponível em: <http://www. mma.gov.br/port/conama/res/res86/res0186.html>. Acesso em: 15mar. 2016

CARNEIRO, Ricardo. Estudos Socioeconômicos Associados à Implantação de Empreendimentos Estratégicos. Belo Horizonte: Editora FJP, 2015.

FEAM. Fundação Estadual do Meio Ambiente. Estudo de Impacto Ambiental — da Barragem de Rejeito do Fundão. Mariana, MG,2005.

. Estudo de Impacto Ambiental - EIA - da Otimização da Barragem de Rejeito do Fundão - Complexo Minerador GermanoAlegria. Sete Soluções e Tecnologia Ambiental. Belo Horizonte, 2012.

. Estudo de Impacto Ambiental - EIA - da Unificação e Alteamento das Barragens de Rejeito do Germano e Fundão. Sete Soluções e Tecnologia Ambiental. Belo Horizonte, 2013. 
. Inventário de Barragem do Estado de Minas Gerais: ano

2015.Belo Horizonte: FEAM, 2016. 54 p.Disponível em: <http:// www.feam.br/images/stories/2016/RESIDUOSMINERA $\%$ C3\%87\% C3\%83O/Invent\%C3\%A1riodeBarragens 2015 Final_V01.pdf $>$. Acesso em: 20maio 2016.

\section{. Relatório Técnico da Diretoria de Qualidade e Gestão}

Ambiental n. ${ }^{\circ} 08$. Belo Horizonte: FEAM, 2007. Disponível em: $<$ http://www.feam.br/images/stories/arquivos/rt_dqga_08_2007.pdf $>$. Acesso em: 20maio 2016.

IBAMA. Instituto Brasileiro do Meio Ambiente e dos Recursos Naturais Renováveis. Impactos ambientais decorrentes do desastre envolvendo o rompimento da barragem de Fundão, em Mariana, Minas Gerais. Laudo Técnico Preliminar. Brasília, DF, 2015.

IBGE. Instituto Brasileiro de Geografia e Estatística. Caderno de Geociências. Disponível em: <https://ww2.ibge.gov.br/home/geociencias/ cartografia/default_territ_area.shtm>. Acesso em: 23 out. 2017. IEF. Instituto Estadual de Florestas. Parecer Único de Compensação Ambiental GCA/DIAP n. ${ }^{\circ}$ 121/2014. Belo Horizonte, 2014.

MEIRELLES, Hely Lopes. Direito administrativo brasileiro. 28.ed. São Paulo: Malheiros, 2003.

JORDANA, Jacint; LEVI-FAUR, David. The politics of regulation in the age of governance. In: JORDANA, Jacint; LEVI-FAUR, David (eds).The politics of regulation: institutions and regulatory reforms for the age of governance. Cheltenhan (UK), Edsward Elgar Publishing, 2004.

MILARÉ, Edis. Direito do Ambiente.São Paulo: Revista dos Tribunais, 
2001.

MINAS GERAIS (Estado). Conselho Estadual de Política Ambiental. Deliberação Normativa ${ }^{\circ}$ 87, de 17 de junho de 2005. Altera e complementa a Deliberação Normativa COPAM nº 62, de 17/12/2002, que dispõe sobre critérios de classificação de contenção de rejeitos, de resíduos e reservatórios de água em empreendimentos industriais e de mineração no Estado de Minas Gerais. Diário [do] Executivo, Belo Horizonte, 18 jun. 2005. [Republicado em 6 set. 2005]. Disponível em: <http://www.siam.mg.gov.br/sla/download.pdf?idNorma=8251 $>$. Acesso em: 25 out. 2017.

. Conselho Estadual de Política Ambiental. Deliberação Normativa $n^{\circ} 124$, de 09 de outubro de 2008. Complementa a Deliberação Normativa COPAM Nº 87, de 06/09/2005, que dispõe sobre critérios de classificação de barragens de contenção de rejeitos, de resíduos e de reservatório de água em empreendimentos industriais e de mineração no Estado de Minas Gerais. Diário [do] Executivo, Belo Horizonte, 15 out. 2008. Disponível em: <http://www.siam. mg.gov.br/sla/download.pdf?idNorma=8572. Acesso em: 25 out. 2017.

. Lei Delegada n. ${ }^{\mathrm{o}}$ 125, de 25 de janeiro de 2007. Dispõe sobre a estrutura orgânica básica da Secretaria de Estado de Meio Ambiente e Desenvolvimento Sustentável. Diário [do] Executivo, Belo Horizonte, 26 jan. 2007. [Revogada]. Disponível em: $<$ http://www. siam.mg.gov.br/sla/download.pdf?idNorma $=6611 \#$ ftn1 $>$. Acesso em: 18 maio 2016.

. Lei n. ${ }^{\circ} 21.972$, de 21 de janeiro de 2016.Dispõe sobre o Sistema Estadual de Meio Ambiente e Recursos Hídricos - Sisema- e dá outras providências.Diário [do] Executivo, Belo Horizonte, 22 jan. 2016a. Disponível em: <http://www.siam.mg.gov.br/sla/download. pdf?idNorma=40095> Acesso em: 25 abr. 2016. 
. Lei n. ${ }^{\circ} 22.073$, de 28 de abril de 2016. Altera Lei ${ }^{\circ}$

21.972, de 21 de janeiro de 2016, que dispõe sobre o Sistema Estadual de Meio Ambiente e Recursos Hídricos - Sisema.Diário [do] Executivo, Belo Horizonte, 29 abr. 2016b. Disponível em: $<$ https://www.almg.gov.br/consulte/legislacao/completa/completa. html?tipo=LEI\&num=22073\&ano=2016> Acesso em: 25 maio 2016.

. Decreto n. ${ }^{\circ} 45.825$,de 20 de dezembro de 2011. Contém o Estatuto da Fundação Estadual do Meio Ambiente.Diário [do] Executivo, Belo Horizonte, 21 dez. 2011. [Revogado]. Disponível em: $<$ http://www.siam.mg.gov.br/sla/download.pdf?idNorma=20035>. Acesso em: 11 maio 2016.

. Decreto n. ${ }^{\circ} 46.993 / 2016,02$ de maio de 2016. Institui a Auditoria Técnica Extraordinária de Segurança de Barragem e dá outras providências.Diário [do] Executivo, Belo Horizonte, 3 maio 2016c. [Retificado em 4 maio 2016]. Disponível em: $<$ http://www. siam.mg.gov.br/sla/download.pdf?idNorma $=41216>$. Acesso em: 10 maio 2016.

\section{. Portal da Transparência do Estado de Minas Gerais.Belo}

Horizonte, 2016. Disponível em: <http://www.transparencia.mg.gov. br/>. Acesso em: 23 maio 2016.

MORAN, Michael. Understanding the Regulatory State. British Journal of Political Science, v. 32, n. 2, p. 391-413, 2002.

MOURA, Marcelo Gameiro. Agências regulatórias no Brasil: os casos dos setores de telecomunicações, eletricidade e petróleo/gás natural. Revista do Serviço Público, v. 53, n. 2, abr.jun., p. 79-113, 2002.

ONUBR. Organização das Nações Unidas. Programa das Nações Unidas para o Meio Ambiente - PNUMA. Disponível em: $<$ https:// 
nacoesunidas.org/agencia/onumeioambiente/ > . Acesso em: 23/05/2016.

SUPRAM. Superintendência Regional de Regularização Ambiental de Juiz de Fora. Parecer Único da Autorização para Exploração Florestal - APEF n. ${ }^{0}$ 05829/2011. Juiz de Fora, 2011.

SUPRAM. Superintendência Regional de Regularização Ambiental Central Metropolitana. Parecer Único n. 262/2013. Belo Horizonte, 2013.

TEIXEIRA, Izabella Mônica Vieira. O uso da avaliação ambiental estratégica no planejamento a oferta de blocos para a exploração e produção de petróleo e gás natural no Brasil: uma proposta. 2008. 308 f. Tese (Doutorado em Ciências em Planejamento Energético) Universidade Federal do Rio de Janeiro, Rio de Janeiro, 2008.

WANDERLEY, Luiz Jardim. Invisibilização e limitações nos Estudos de Impacto Ambiental: elementos técnicos e políticos do desastre em Mariana-MG. Apresentação do Grupo POEMAS: Política, Economia, Mineração, Ambiente e Sociedade. UFJF: Juiz de Fora, 2016.Disponível em: <http:/www.cetem.gov.br/images/palestras/2015/mariana/14-luizjardim-wanderley.pdf>. Acesso em: 21 mar. 2016.

Como citar: CÉSAR, Paulo Sérgio Mendes; CARNEIRO, Ricardo. A gestão ambiental em Minas Gerais e o rompimento da barragem de rejeitos do fundão em Mariana/MG. Revista do Direito Público, Londrina, v. 13, n. 2, p.230-266, ago. 2018. DOI: 10.5433/24157-108104-1.2018v1 3n2p230. ISSN: 1980-511X.

Recebido em: 20/08/2017 Aprovado em: 17/05/2018 